\title{
TEORIAS DA APRENDIZAGEM EM PUBLICAÇÕES NA ÁREA DE EDUCAÇÃO EM ENGENHARIA: UM MAPEAMENTO COM FOCO NA DISCIPLINA DE CÁLCULO I
}

\author{
EDINÉIA ZARPELON ${ }^{1}$ \\ ORCID: https://orcid.org/0000-0002-4715-1450 \\ LUIS MAURICIO RESENDE 2 \\ ORCID: https://orcid.org/0000-0003-4151-0843
}

\begin{abstract}
RESUMO: O objetivo principal desta pesquisa foi identificar quais teorias da aprendizagem fundamentam a ação docente e são referenciadas em trabalhos voltados para a disciplina de Cálculo I. Para tanto, foi realizado um levantamento a partir da produção acadêmica brasileira divulgada no Congresso Brasileiro de Educação em Engenharia no período 2010-2017. Sendo assim, por meio de uma pesquisa bibliográfica de caráter qualitativo, 23 trabalhos foram eleitos para constituir o portfólio final desta investigação. Assim, foi possível observar que a maioria dos estudos são de natureza empírica $(\mathrm{n}=15)$, com abordagem exclusivamente cognitivista $(\mathrm{n}=17)$, e que Vygotsky foi o teórico mais citado $(n=12)$, seguido por Piaget $(n=9)$ e Ausubel $(n=5)$. Além disso, notou-se um equilíbrio em relação à utilização das obras relacionadas nas referências bibliográficas, especialmente em três produções: Pedagogia da Autonomia (FREIRE, 1996), Pensamento e Linguagem (VYGOTSKY, 1989) e A formação social da mente: o desenvolvimento dos processos psicológicos superiores (VYGOTSKY, 1998). Por fim, os resultados sugerem a predominância de trabalhos sem embasamento teórico adequado $(\mathrm{n}=13)$ ou embasados parcialmente $(\mathrm{n}=6)$, segundo os critérios estabelecidos nesta investigação.
\end{abstract}

Palavras-chave: Teorias da Aprendizagem. Cálculo I. Mapeamento.

\section{LEARNING THEORIES IN PUBLICATIONS IN THE ENGINEERING EDUCATION AREA: MAPPING FOCUSED IN THE CALCULUS I SUBJECT}

\begin{abstract}
The main aim of this paper was to identify which learning theories base the teaching acts and are also referred to the Calculus I subject. Therefore, a lift was made about the Brazilian academic production released in the Brazilian Congress of Engineering Education during 2010-2017. Thus, through a qualitative bibliographic research, 23 papers were selected to constitute this final investigation portfolio. Most results, was possible to notice, are of empirical nature $(\mathrm{n}=15)$, with exclusively cognitivist approach ( $n=17)$, in which Vygotsky was the most mentioned theorist $(n=12)$, followed by Piaget $(n=9)$ and Ausubel $(\mathrm{n}=5)$. Furthermore, there was a balance in the use of the works related to the bibliographic references specially in three productions: Pedagogy of Autonomy (FREIRE, 1996) Thought and Language (VYGOTSKY, 1989) and Mind in Society: The Development of Higher Psychological Processes (VYGOTSKY,
\end{abstract}

\footnotetext{
${ }^{1}$ Universidade Tecnológica Federal do Paraná. Curitiba-PR/Brasil<ezarpelon@utfpr.edu.br>

${ }^{2}$ Universidade Tecnológica Federal do Paraná. Curitiba-PR/Brasil <lmresende@utfpr.edu.br> Educação em Revista|Belo Horizonte|v.36|e210405|2020
} 
1998). Finally, the results suggest the predominance of papers without proper theoretical basis $(\mathrm{n}=13)$ or partially based $(n=6)$, according to the criteria established in this research.

Keywords: Learning Theories. Calculus I Subject. Mapping.

\section{TEORÍAS DEL APRENDIZAJE EN PUBLICACIONES EN EL ÁREA DE EDUCACIÓN DE INGENIERÍA: UN MAPEO CON UN ENFOQUE EN LA DISCIPLINA DE CÁLCULO I}

RESÚMEN: El objetivo principal de esta investigación fue identificar qué teorías del aprendizaje fundamentan la acción docente y son referenciadas en trabajos orientados a la disciplina de Cálculo I. Com este fin, fue realizado un estudio a partir de la producción académica brasileña divulgada en el Congreso Brasileño de Educación en Ingeniería en el período 2010-2017. Así, por medio de una encuesta bibliográfica de carácter cualitativo, 23 trabajos fueron elegidos para constituir el portafolio final de esta investigación. Pues, se ha observado que la mayoría de los estudios son de naturaleza empírica $(\mathrm{n}=15)$, con enfoque exclusivamente cognitivista $(n=17)$, y que Vygotsky fue el teórico más citado $(n=12)$, seguido de Piaget $(n=9)$ y Ausubel $(n=5)$. Además, se notó un equilibrio en relación con la utilización de las obras relacionadas en las referencias bibliográficas, especialmente en tres producciones: Pedagogía de la Autonomía (FREIRE, 1996), Pensamiento y Lenguaje (VYGOTSKY, 1989) y La formación social de la mente: el desarrollo de los procesos psicológicos superiores (VYGOTSKY, 1998). Por último, los resultados sugieren la predominancia de trabajos sin base teórica adecuada $(n=13)$ o basados parcialmente $(n=6)$, según los criterios establecidos en esta investigación.

Palabras clave: Teorías del Aprendizaje. Cálculo I. Mapeo.

\section{INTRODUÇÃO}

Refletir e estudar sobre a aprendizagem, buscando entender o porquê determinados comportamentos são adotados ou extintos, a razão pela qual algumas pessoas aprendem e outras não e quais variáveis interferem (potencializando ou impedindo) sua ocorrência, são indagações que deveriam fazer parte dos sujeitos que trabalham intermediando processos de ensino-aprendizagem. Essa afirmação está amparada no fato de que uma pessoa pode aprender em circunstâncias fortuitas, a partir de situações informais ou a aprendizagem pode ser resultado de uma ação planejada e intencional, como no caso da sala de aula (LA ROSA, 2007). Logo, considerando que o objetivo maior da ação docente - em sala de aula - é a aprendizagem do aluno, todos os aspectos associados a ela deveriam ser priorizados.

No que se refere ao meio acadêmico, Fontana (1991) defende que as descrições do que acontece quando a aprendizagem se concretiza " [...] auxiliam os professores a planejarem as estratégias de sala de aula, a monitorarem o progresso dos alunos e a isolarem as possíveis razões para o sucesso ou falha nessa aprendizagem" (FONTANA, 1991, p. 168). Tais descrições se constituem como parte de um corpo maior de informações chamadas teorias de aprendizagem (ou teorias do comportamento) as quais, por sua vez, também ajudam os professores a entenderem fenômenos relacionados à aprendizagem.

Portanto, assume-se que, implícita ou explicitamente, consciente ou inconscientemente, "[...] toda pessoa que ensina tem uma teoria da aprendizagem [...]" (BIGGE, 1977, p. 6) imbricada em sua ação. Em particular, a ação educativa docente - desde que exercida em situações planejadas - é sempre intencional e subjacente a ela existe uma teoria associada (MIZUKAMI, 2011). Sendo assim, essa prática também é orientada pela concepção de aprendizagem que o professor assume (BECKER, 2008; TUNES; TACCA; MARTÍNEZ, 2006).

Consequentemente, a preparação de uma aula, a seleção do material a ser utilizado e as técnicas escolhidas para abordar o conteúdo estão atreladas a tal concepção. Nesse sentido, uma teoria 
de aprendizagem pode ser um instrumento de análise, permitindo que seus seguidores avaliem a qualidade de uma situação em sala de aula (BIGGE, 1977).

Dessa maneira, com base no que foi exposto, é possível afirmar que há uma justificativa nas pesquisas sobre teorias de aprendizagem que permeiam o cotidiano escolar e acadêmico. Sendo assim, na concepção de Oliveira, Araujo e Veit (2017):

[...] as teorias de aprendizagem são importantes, dentre outros aspectos, porque possibilitam aos professores adquirirem conhecimentos, atitudes, crenças, habilidades, fundamentais para atingir os objetivos de ensino; são elas que norteiam as práticas didáticas dos professores. Sem fundamentação teórica de aprendizagem, entendemos que as práticas de um professor tendem a tornar-se um tanto intuitivas, beirando a tentativa e erro (OLIVEIRA; ARAUJO; VEIT, 2017, p. 15).

Entretanto, Jesus (2014) relata existir uma lacuna no que diz respeito aos estudos que investigam as Teorias de Aprendizagem sob o olhar dos indicadores de produção e conteúdo, referindose especificamente à área de Educação em Ciências. Por isso, em sua dissertação de mestrado, a pesquisadora traçou um perfil das teorias de aprendizagem nos principais periódicos da área supramencionada.

Contudo, infere-se que esta lacuna também exista quando se considera a Educação em Engenharia ${ }^{1}$. Apesar de ter crescido o interesse entre os docentes de cursos de Engenharia em discutir e analisar os processos de ensino-aprendizagem visando, especialmente, adequar seus procedimentos pedagógicos a uma nova realidade (LODER, 2002), não foram identificados trabalhos voltados a esta temática: investigar as teorias de aprendizagem subjacentes aos trabalhos na área de Educação em Engenharia.

Uma aproximação a esta proposta foi identificada na pesquisa de Gomes et al. (2010) realizada com alunos na área de Ciências Exatas de uma universidade privada. Os autores buscaram analisar as preferências de aprendizagem desses alunos, de modo a verificar quais aspectos das principais teorias de aprendizagem caracterizam-se como mais adequados ao perfil dos alunos pesquisados. Dentre os resultados esperados, os autores argumentam "[...] buscar a melhoria no ensino fundamentada nas características das teorias de aprendizagem” (GOMES et al., 2010, p. 697).

Paralelamente a isso, as dificuldades apresentadas por alunos em relação à matemática em todos os níveis de ensino - cristalizadas por meio dos resultados insatisfatórios - têm motivado a realização de estudos e diversas discussões no meio acadêmico, tanto no âmbito nacional quanto internacional. Nesse sentido, o fracasso na matemática:

[...] levou os professores a procurarem diversas estratégias e alternativas metodológicas que motivassem e facilitassem a compreensão dos conteúdos. No entanto, esta procura tem provocado a conscientização da influência de uma base teórica para fundamentar a prática [...]" (RODRIGUEZ, 1993, apudLEHMANN, 2010, p. 1, grifos nossos).

Em particular, quando se considera o ensino superior, mais especificamente os cursos de Engenharia, tem-se a disciplina de Cálculo Diferencial e Integral I (ou Cálculo I) integrando o rol daquelas em que os alunos apresentam grandes dificuldades e, consequentemente, índices de reprovação preocupantes.

Assim, tendo em vista a área de Educação em Engenharia e o componente curricular Cálculo I, define-se o objetivo desta investigação: mapear a produção acadêmica brasileira divulgada no Congresso Brasileiro de Educação em Engenharia (COBENGE) no período 2010-2017, com vistas a identificar quais teorias da aprendizagem fundamentam a ação docente e são referenciadas nos trabalhos voltados à disciplina de Cálculo Diferencial e Integral I. Também, pretende-se contribuir com a Educação em Engenharia apresentando um balanço, ainda que parcial e provisório, apontando tendências e possibilitando que novas perspectivas para a área possam despontar.

A escolha por avaliar trabalhos do COBENGE é justificada pelo fato de que este é o fórum de reflexão sobre educação em Engenharia mais importante do país. Nele, representantes de instituições de ensino, professores, órgãos governamentais e outras entidades, reúnem-se a fim de que possam “[...] 
compartilhar experiências, promover debates e propor estratégias para formar profissionais cada vez mais qualificados e capacitados para o atendimento das necessidades do país" (TOZZI; DUTRA, 2013, p. 26).

No entanto, apesar de eventos como o COBENGE trazerem impactos positivos em relação aos cursos da área de Engenharia (visto os relatos de alterações nas grades curriculares, estudos sobre a carga horária das disciplinas, reflexões sobre estágios e trabalhos de conclusão de curso, sobre índices de retenção e evasão, etc.), os processos de aprendizagem são relegados a um segundo plano (ARAÚJO et al., 2011). Para Araújo e seus colaboradores (2011), isso revela a carência de discussões sobre esse tema e reforça a necessidade de que investigações na área de Educação em Engenharia sejam desenvolvidas com foco específico nos processos de aprendizagem.

Por fim, cabe esclarecer que a presente investigação levará em consideração os teóricos citados nas obras de Lefrançois (2016) e Moreira (2011), a saber: Ausubel, Bandura, Bruner, Freire, Gagné, Gowin, Guthrie, Hebb, Hull, Kelly, Laird, Novak, Pavlov, Piaget, Rogers, Skinner, Thorndike, Vergnaud, Vygotsky e Watson. Critério semelhante a este foi utilizado na obra de Jesus (2014).

\section{A APRENDIZAGEM E SUAS ABORDAGENS TEÓRICAS}

A maioria dos psicólogos concorda que "[...] aprendizagem é uma mudança relativamente persistente, no comportamento potencial de um indivíduo, devido à experiência" (FONTANA, 1991, p. 166). Fontana (1991) ainda reforça três aspectos implícitos nesta definição: 1) a aprendizagem muda o indivíduo de alguma forma; 2) essa mudança (que pode ocorrer num nível simples ou complexo) é fruto da experiência, excluindo, portanto, as mudanças provenientes da maturação e do desenvolvimento físico; 3) a mudança ocorre mais no desempenho potencial que real. Isto quer dizer que é possível aprender algo em determinado instante e só demonstrar ou manifestar essa aprendizagem no desempenho real muito tempo depois.

A definição adotada por Lefrançois (2016) é muito semelhante: aprendizagem é “[...] toda mudança relativamente permanente no potencial de comportamento, que resulta da experiência, mas não é causada por cansaço, maturação, drogas, lesões ou doença" (LEFRANÇOIS, 2016, p. 5). O autor argumenta que ao ingerir drogas, por exemplo, o comportamento de uma pessoa pode mudar radicalmente, no entanto, essa mudança não caracteriza uma aprendizagem. Assim, exclui de sua definição as mudanças de comportamento advindas de cansaço, ingestão de drogas, resultantes de lesões ou doenças e as biologicamente determinadas como, por exemplo, crescimento ou maturação sexual. Lefrançois (2016) ainda esclarece que a aprendizagem implica mudanças na capacidade (habilidades ou conhecimentos necessários para fazer algo) e na disposição (inclinação para fazer ou não fazer algo).

Outrossim, a aprendizagem "[...] envolve uma mudança duradoura no indivíduo vivo, não marcada por sua herança genética. Pode ser uma mudança por insights, de comportamento, de percepção ou de motivação, ou ainda uma combinação desses elementos" (BIGGE, 1977, p. 1). Além disso, de acordo com Antunes (2014, p. 17) “[...] a aprendizagem é um processo de construção, ressignificação, sistematização, valorização e apropriação de saberes cotidianos geradores de transformações permanentes ou relativamente permanentes no aprendiz".

Sendo assim, na busca pelo entendimento dos aspectos que caracterizam a aprendizagem, surgem as Teorias da Aprendizagem (TA), definidas como tentativas sistemáticas de explicar e compreender como ocorrem as mudanças no comportamento (LEFRANÇOIS, 2016). Nessa perspectiva, segundo a concepção de Moreira (2011, p. 12) “[...] uma teoria é uma tentativa humana de sistematizar uma área de conhecimento, uma maneira particular de ver as coisas, de explicar e prever observações, de resolver problemas". Logo, uma TA é uma construção humana que busca interpretar sistematicamente a área de conhecimento chamada de aprendizagem (MOREIRA, 2011).

Por sua vez, alinhadas a estas teorias - constituídas de conceitos e princípios - encontramse os sistemas de valores, definidos por Moreira (2011) como filosofias ou visões de mundo ou, ainda, denominados "enfoques teóricos" ou "abordagem teórica". No caso das TA, são três enfoques: o comportamentalismo ou behaviorismo, o cognitivismo ou construtivismo e o humanismo. 
Em síntese, o comportamentalismo tem como pressuposto principal que o comportamento é controlado por suas consequências: se a consequência for agradável para o aprendiz, possivelmente haverá o aumento na frequência da conduta (comportamento); se a consequência for desagradável, haverá a diminuição da conduta que gerou aquela consequência. Assim, não há necessidade de se preocupar com as atividades mentais ou com os constructos intermediários entre estímulo e resposta, uma vez que o behaviorismo defende que manipulando eventos posteriores à exibição de comportamento é possível controlá-los (MOREIRA, 2011). Os principais representantes desse enfoque são: Pavlov, Watson, Guthrie, Thorndike e Skinner.

Por sua vez, o cognitivismo parte da premissa que o conhecimento é construído (construtivismo), em outras palavras, a ênfase está no ato de conhecer, na cognição (MOREIRA, 2011). Os psicólogos cognitivistas preocupam-se com os "processos centrais" do sujeito, tais como: organização do conhecimento, processamento de informações, estilos de pensamento e comportamentos associados à tomada de decisões, aspectos esses que dificilmente são observáveis (MIZUKAMI, 2011). Nesta abordagem as emoções são consideradas articuladas com o conhecimento e a aprendizagem é entendida como algo "[...] mais que um produto do ambiente, das pessoas ou de fatores que são externos aos alunos" (MIZUKAMI, 2011, p. 59). Seus principais representantes são: Piaget, Bruner, Vygotsky, Vergnaud, Ausubel e Kelly.

A filosofia humanista, segundo esclarece Moreira (2011), enxerga o aprendiz primeiramente como pessoa, considerando-o como um todo, isto é, preocupando-se com seus sentimentos, pensamentos e ações. Assim, o humanismo defende que esses três elementos (pensamentos, sentimentos e ações) não podem ser entendidos de forma dissociada, uma vez que estão integrados e intrinsecamente ligados ao intelecto. Os principais teóricos desse enfoque são: Novak, Gowin, Rogers e Freire.

Para Moreira (2011) inúmeras teorias de cunho comportamentalista, cognitivista ou humanista podem fornecer subsídios para a prática docente. Por este motivo, com base na síntese apresentada e considerando os teóricos representantes de cada enfoque, iniciou-se o processo de busca por estudos que aliassem alguma TA ao ensino da disciplina de Cálculo I.

\section{PERCURSO METODOLÓGICO}

\section{DESCRIÇÃO DA PESQUISA}

Quanto aos objetivos, esta pesquisa é de cunho descritivo. Cabe mencionar que o termo "mapeamento da pesquisa" é entendido como "[...] um processo sistemático de levantamento e descrição de informações acerca das pesquisas produzidas sobre um campo específico de estudo, abrangendo um determinado espaço (lugar) e período de tempo" (FIORENTINI et al., 2016, p. 18).

Com relação aos procedimentos, esta pesquisa se caracteriza como bibliográfica, visto que foi elaborada com base em publicações oriundas do COBENGE e "[...] tem como princípio básico conhecer as diferentes formas de contribuição científica que se realizaram sobre determinado assunto ou fenômeno" (OLIVEIRA NETTO, 2008, p. 30). Logo, compreende-se que na área de Educação em Engenharia as TA não estão cristalizadas o suficiente, portanto, são necessárias pesquisas que tragam à luz essa temática. Por fim, do ponto de vista da forma de abordagem do problema, a pesquisa caracterizase como qualitativa.

\section{DESCRIÇÃO DO PROTOCOLO DE PESQUISA}

A fim de promover a transparência dos métodos, processos e análises a serem realizadas, segue descrito na sequência o protocolo de pesquisa.

\section{Pergunta de pesquisa}

Este estudo foi impulsionado pelo seguinte questionamento: quais teorias da aprendizagem fundamentam a ação docente e são referenciadas nas publicações do Congresso Brasileiro de Educação em Engenharia (COBENGE), cujo foco seja a disciplina de Cálculo Diferencial e Integral I? 
Além desta, outras perguntas secundárias subsidiaram este mapeamento: (a) Como estes trabalhos são classificados: teóricos ou empíricos?, (b) Quais são as filosofias (ou abordagens teóricas) explícitas ou implícitas nos trabalhos?, (c) Quais são os teóricos mais citados?, (d) Quais obras?, (e) Que conceitos?, (f) Os trabalhos estão realmente embasados nas TA citadas?

\section{Critérios estabelecidos para a coleta de dados}

Neste artigo, tomou-se como campo de estudo as TA implícitas em trabalhos voltados à disciplina de Cálculo Diferencial e Integral I e delimitou-se como espaço de produção os trabalhos acadêmicos divulgados no COBENGE.

O universo da pesquisa foi composto de 3.870 artigos, extraídos dos anais do COBENGE, no período de 2010-2017.

\section{Seleção dos trabalhos}

O procedimento inicial foi a leitura do título e resumo dos trabalhos, visando identificar aqueles voltados à disciplina de Cálculo Diferencial e Integral I. Os trabalhos com menção à disciplina foram separados dos demais e tiveram suas referências bibliográficas analisadas. Isso permitiu categorizálos em "teóricos" e "sem teóricos."

A categoria "teóricos" indicava que o trabalho continha em suas referências ao menos um dos teóricos da aprendizagem citados em Lefrançois (2016) e/ou Moreira (2011), detalhados na introdução deste artigo. Cabe esclarecer que um trabalho (Palheta et al., 2017) classificado inicialmente como "sem teóricos" foi acrescentado à amostra pelo fato de conter nas referências uma obra intitulada Teorias de Aprendizagem, semelhante aos títulos das obras de Moreira (2011) e Lefrançois (2016).

$\mathrm{Na}$ sequência, realizou-se a leitura integral dos trabalhos a fim de eleger definitivamente aqueles alinhados com a proposta de pesquisa. Nesta fase, foram excluídos os trabalhos que não tinham como foco a disciplina de Cálculo I, mas apenas a mencionavam no resumo para justificar dificuldades acadêmicas, reprovações e evasões. Optou-se por manter trabalhos voltados às disciplinas básicas desde que Cálculo I figurasse no rol e que a coleta de dados ou a aplicação do trabalho tivesse relação com este componente curricular.

Por fim, foi realizada a leitura integral dos trabalhos voltados ao Cálculo I $(n=75)$ e classificados como "sem teóricos" a fim de confirmar se a separação estava correta. Neste caso, 4 trabalhos foram agregados à amostra, uma vez que mencionavam teóricos que são foco da investigação em tela, mas não indicavam isso nas referências bibliográficas.

Ao final deste processo, o portfólio bibliográfico ficou constituído de 23 artigos que estavam alinhados com o problema de pesquisa. O número de trabalhos selecionados em cada etapa segue apresentado cronologicamente na tabela 1.

Tabela 1. Artigos publicados no COBENGE no período 2010 a 2017

\begin{tabular}{|cccccccccc|}
\hline Artigos & $\mathbf{2 0 1 0}$ & $\mathbf{2 0 1 1}$ & $\mathbf{2 0 1 2}$ & $\mathbf{2 0 1 3}$ & $\mathbf{2 0 1 4}$ & $\mathbf{2 0 1 5}$ & $\mathbf{2 0 1 6}$ & $\mathbf{2 0 1 7}$ & Total \\
\hline Total & 355 & 471 & 424 & 510 & 575 & 379 & 535 & 621 & $\mathbf{3 . 8 7 0}$ \\
\hline Foco em CDI I & 05 & 10 & 08 & 10 & 09 & 09 & 08 & 16 & $\mathbf{7 5}$ \\
\hline Sem TA & 04 & 05 & 04 & 08 & 07 & 08 & 07 & 09 & $\mathbf{5 2}$ \\
\hline Com TA & 01 & 05 & 04 & 02 & 02 & 01 & 01 & 07 & $\mathbf{2 3}$ \\
\hline
\end{tabular}

Fonte: Os autores (2018)

\section{Critérios para seleção das informações que compõem o mapeamento}

Num primeiro momento, os 23 trabalhos que formam a amostra final foram examinados com o intuito de levantar as seguintes características: (a) classificação: estudos teóricos ou empíricos, (b) filosofia subjacente: behaviorista, cognitivista ou humanista, (c) teóricos citados nos estudos e (d) obras referenciadas. 
Em seguida, realizou-se uma análise de como estes trabalhos poderiam ser classificados segundo a fundamentação teórica (relacionada à TA) apresentada. Para tanto, foram definidas três categorias: (a) não embasado, (b) parcialmente embasado e (c) fortemente embasado. A análise que pautou essas categorizações se deu por meio da utilização dos conceitos principais relacionados às TA citadas nos trabalhos. A relação dos conceitos e descrição dos parâmetros utilizados segue apresentada na seção de resultados e discussão.

\section{RESULTADOS E DISCUSSÃO}

Os dados, ilustrados por meio da tabela 1 , revelam que a quantidade de pesquisas que aliam o ensino de Cálculo I com as teorias de aprendizagem é pequena $(n=23)$ quando comparada à quantidade total de trabalhos publicados no evento, considerando o recorte temporal escolhido.

Apesar da continuidade, destaca-se a pouca variação na quantidade de trabalhos publicados no decorrer dos anos. É possível observar que praticamente $70 \%$ dos estudos concentram-se nos anos de 2011 ( $\mathrm{n}=5), 2012(\mathrm{n}=4)$ e $2017(\mathrm{n}=7)$.

Considerando apenas a produção voltada para a disciplina de Cálculo I, percebe-se que estes 23 estudos os quais caracterizam a amostra desta investigação representam 31\% dos trabalhos. Estes trazem considerações sobre as TA, em maior ou menor grau, com maior ou menor profundidade. Portanto, há indicativos de que parte significativa dos autores reconhecem a importância de uma base teórica para fundamentar trabalhos com foco na disciplina em questão.

Tal resultado corrobora parcialmente a conclusão de Gomes (2012) no momento em que a autora compara os resultados obtidos em seu mapeamento com os resultados alcançados em outros dois trabalhos semelhantes ${ }^{2}$, a qual destaca a existência de um "[...] significativo aumento de artigos pautados em pesquisas na área de Educação Matemática ou que apontam para estudos embasados em teorias de aprendizagem" (GOMES, 2012, p. 8). No período de 2007-2011, Gomes (2012) verificou que 7 de 26 trabalhos analisados estavam relacionados às pesquisas ou teorias. Esses trabalhos relatavam pesquisas na área de Educação Matemática ou discutiam teorias de aprendizagem.

O discurso de Lehmann (2010) também aduz que, devido ao elevado número de reprovações, o processo de ensino-aprendizagem dos conteúdos de Cálculo I tem sido estudado por diversos pesquisadores. Há trabalhos que englobam metodologias de ensino e "[...] diversos estudos no campo da psicologia e do desenvolvimento cognitivo" (LEHMANN, 2010, p. 1). A autora reforça que essas discussões são importantes, tanto para entender o processo de aprendizagem quanto para buscar alternativas a fim de melhorar o ensino da disciplina.

Quanto à classificação, quinze pesquisas $(65 \%)$ são de natureza empírica, isto é, tiveram como base a coleta e apresentação de evidências ou dados originais para apoiar as alegações levantadas nos estudos (YIN, 2016). Portanto, nessa categoria estão inseridos os estudos que apresentam experiências de ensino, desenvolvidas com professores e/ou alunos. As demais $(n=8)$ são pesquisas de natureza teórica.

Os dados da tabela 2 revelam a existência de desequilíbrio em relação ao enfoque teórico adotado nos trabalhos, sendo predominante aqueles com abordagem exclusivamente cognitivista $(\mathrm{n}=17)$. Foram identificados três trabalhos mencionando um único teórico humanista, todos publicados em 2017 (Xavier e Xavier, 2017; Bueno e Silva, 2017; Costa et al., 2017), dois mencionando teóricos do behaviorismo e cognitivismo (Pereira Filho, Kaiber e Lélis, 2012; Lehmann, 2010) e um trabalho mencionando um teórico cognitivista e outro humanista (Gerab e Trentin, 2015).

Tabela 2. Distribuição segundo a filosofia e os teóricos da aprendizagem citados

Filosofia

$\begin{array}{ll} & \text { Ausubel } \\ & \text { Bruner } \\ \text { Cognitivismo } & \text { Piaget } \\ & \text { Vygotsky } \\ & \text { Ausubel e Vygotsky }\end{array}$

Trabalhos

02

01

03

06

01 


\begin{tabular}{|cll}
\hline & Piaget e Vygotsky & 01 \\
& Ausubel, Vygotsky e Piaget & 01 \\
& Piaget, Vergnaud e Vygotsky & 02 \\
Humanismo & Freire & 03 \\
Behaviorismo e & Thorndike e Piaget & 01 \\
Cognitivismo & Watson, Pavlov, Guthrie e & 01 \\
\hline Cognitivismo e Humanismo & Skinner, Piaget e Vygotsky & 01 \\
\hline & Total & $\mathbf{2 3}$
\end{tabular}

Fonte: Os autores (2018)

Observa-se na tabela 2 que quinze trabalhos mencionavam em seu escopo apenas um teórico da aprendizagem, ao passo que oito trabalhos citavam dois ou mais. Vygotsky foi o teórico com maior número de menções, figurando em 12 dos 23 trabalhos analisados (ou 52\%). Em seguida, destacam-se Piaget $(n=9)$ e Ausubel $(n=5)$, cuja representatividade equivale a $39 \%$ e $21 \%$, respectivamente. Dessa forma, é possível inferir que as teorias sociointeracionista, de Vygotsky, desenvolvimentista-cognitiva, de Piaget e da aprendizagem significativa, de Ausubel, são as predominantes.

Ainda que a amostra deste estudo seja de menor escopo em relação aos 1.206 artigos analisados por Jesus (2014), realizado com base na consulta a quatro periódicos da área de Educação em Ciências, os resultados se aproximam. Na pesquisa mencionada, Piaget, Vygostsky, Freire e Ausubel foram, nesta ordem, os teóricos mais citados. Nota-se, na comparação com os dados deste mapeamento, uma inversão em relação às posições, porém, no rol das quatro primeiras posições figuram os mesmos teóricos. Além disso, entre os nove autores mais citados na pesquisa de Jesus (2014), seis são representantes de teorias cognitivas, demonstrando o predomínio deste enfoque sobre os demais, compactuando, portanto, com os resultados deste mapeamento.

Os resultados obtidos em relação aos referenciais teóricos são mais otimistas que os obtidos no estudo de Oliveira, Araujo e Veit (2017), tendo em vista que esses autores fizeram uma revisão de literatura acerca da resolução de problemas no ensino de física, traçando um panorama da produção acadêmica nos últimos 20 anos. Para isso, foram consultados os principais periódicos nacionais e internacionais $(\mathrm{n}=22)$ e diferentes plataformas de dados, que resultaram em 47 artigos. Os autores constataram que "[...] os artigos não adotam embasamento teórico associado a teorias de aprendizagem e concepções epistemológicas” (OLIVEIRA; ARAUJO; VEIT, 2017, p. 12). Mencionam que: (a) existem poucas e superficiais referências a fundamentos das teorias de Vygotsky, (b) somente um trabalho deixa explícito basear-se nos pressupostos de Freire e (c) apenas um trabalho fundamenta-se nas concepções da teoria dos campos conceituais de Vergnaud.

Ao analisar as listas de referências bibliográficas, verifica-se que a maioria dos estudos $(n=10)$ ampara-se apenas em uma produção (livro, artigo, anais de eventos) para citar o teórico ou a TA. Parte dos trabalhos referenciam duas $(n=4)$ ou três obras $(n=3)$ obras. Dois trabalhos, citando Piaget, utilizamse de sete e oito referências, respectivamente. Observou-se ainda que quatro trabalhos mencionavam algum teórico, porém nenhuma referência bibliográfica estava associada a eles. Neste caso, dois trabalhos (Pereira e Pasco, 2017; Moriel Junior e Alencar, 2017) eram associados a Vygotsky, um (Macambira e Athayde, 2014) a Piaget e Vygotsky e um (Pereira Filho, Kaiber e Lélis, 2012) a Piaget e Thorndike.

Além disso, notou-se que um dos trabalhos (Kessler, Py, Manzini e Lemos, 2011), o qual menciona Piaget, Vygotsky e Vergnaud, apresenta citações diretas deste último teórico, todavia a(s) obra(s) da(s) qual(is) as citações foram retiradas não consta(m) nas referências bibliográficas. Ademais, um trabalho (LEHMANN, 2010) faz menção aos behavioristas Watson, Pavlov, Guthrie e Skinner, porém, nenhuma referência bibliográfica é associada a eles.

Quanto à diversidade, percebe-se que o teórico que teve mais obras listadas nas referências bibliográficas foi Piaget $(n=15)$, seguido por Vygotsky $(n=7)$ e Ausubel $(n=4)$. O quadro 1 apresenta os títulos dessas obras, bem como o quantitativo de trabalhos que as referenciaram.

Quadro 1. Títulos das obras associadas as TA listadas nas referências bibliográficas 


\begin{tabular}{|c|c|}
\hline Teórico & Título da obra referenciada (número de vezes que foi referenciada) \\
\hline Ausubel & $\begin{array}{l}\text { Aquisição e retenção de conhecimentos: uma perspectiva cognitiva }{ }^{3}(n=2) \text {. } \\
\text { Aprendizagem significativa: a teoria e textos complementares }(n=1) . \\
\text { Aprendizagem significativa: a teoria de David Ausubel }(n=2) \\
\text { Teoria da aprendizagem significativa segundo Ausubel }(n=1) \text {. }\end{array}$ \\
\hline Bruner & Teorias de Aprendizagem $(n=1)$ \\
\hline Freire & Pedagogia da Autonomia $(n=3)$ \\
\hline Novak & A teoria subjacente aos mapas conceituais e como elaborá-los e usá-los ( $\mathrm{n}=1)$. \\
\hline Piaget & $\begin{array}{l}\text { Psicologia e Pedagogia }(n=1) \text {. } \\
\text { L’évolution intellectuelle entre l'adolescence et l'âge adulte }(n=1) \text {. } \\
\text { Epistemologia Genética }(n=1) \text {. } \\
\text { Seis estudos de Psicologia }(n=2) \text {. } \\
\text { Da lógica da criança à lógica do adolescente: ensaio sobre a construção das } \\
\text { estruturas formais ( } n=2) \text {. } \\
\text { Abstração reflexionante relações lógico-aritméticas e ordem das relações espaciais } \\
(n=1) \text {. } \\
\text { A psicologia da criança }(n=1) \text {. } \\
\text { Para onde vai a educação? }(n=1) \text {. } \\
\text { Psicologia e epistemologia: por uma teoria do conhecimento }(n=1) \text {. } \\
\text { Psicologia e epistemologia genética de Jean Piaget }(n=1) \text {. } \\
\text { O método clínico: usando os exames de Piaget ( } n=2) \text {. } \\
\text { A psicologia do desenvolvimento de Jean Piaget }(n=1) \text {. } \\
\text { Piaget na sala de aula ( } n=1) \text {. } \\
\text { O período de desenvolvimento das operações formais na perspectiva piagetiana: } \\
\text { aspectos mentais, sociais e estrutura ( } n=2) \text {. } \\
\text { O ensino de matemática: contributos pedagógicos de Piaget e Vygotsky ( } n=1) \text {. }\end{array}$ \\
\hline Vergnaud & $\begin{array}{l}\text { A teoria dos campos conceituais }(n=1) \text {. } \\
\text { A teoria dos campos conceituais de Vergnaud, o ensino de ciências e a investigação } \\
\text { nesta área }(n=1) \text {. }\end{array}$ \\
\hline Vygotsky & $\begin{array}{l}\text { Pensamento e Linguagem }(n=3) \text {. } \\
\text { A formação social da mente: o desenvolvimento dos processos psicológicos } \\
\text { superiores ( } n=3) \text {. } \\
\text { Psicologia Pedagógica }(n=1) \text {. } \\
\text { Mediação da Aprendizagem: contribuições de Feuerstein e de Vygotsky }(n=1) \text {. } \\
\text { Atividades experimentais de demonstrações em sala de aula: uma análise segundo o } \\
\text { referencial da teoria de Vygotsky }(n=1) \text {. } \\
\text { Vygotsky: aprendizado e desenvolvimento: um processo sócio-histórico }(n=2) \text {. } \\
\text { O ensino de matemática: contributos pedagógicos de Piaget e Vygotsky }(n=1) \text {. }\end{array}$ \\
\hline
\end{tabular}

Fonte: Os autores (2018)

Posto isso, é possível notar um equilíbrio em relação à quantidade de vezes que cada obra foi referenciada, destacando-se levemente três produções: um livro de Paulo Freire (Pedagogia da Autonomia) e dois de Levy Vygotsky (Pensamento e Linguagem e A formação social da mente: o desenvolvimento dos processos psicológicos superiores) que foram referenciados três vezes nos trabalhos avaliados na pesquisa em tela.

Quanto à classificação em função do embasamento teórico apresentado, optou-se por utilizar como descritores os principais conceitos de cada teoria da aprendizagem e verificar se estes foram ou não citados nos trabalhos. Os conceitos (ou descritores) eleitos como representantes das TA seguem apresentados por meio do quadro 2.

Quadro 2. Principais descritores associados a cada TA 


\begin{tabular}{|c|c|c|}
\hline Abordagem & Teórico & Conceitos-chave da teoria \\
\hline Behaviorista & Thorndike & $\begin{array}{l}\text { Estímulo, resposta, reforço, conexões neurais (ou conexões } \\
\text { mentais), lei do efeito, lei do exercício, lei da prontidão, sets. }\end{array}$ \\
\hline \multirow{5}{*}{ Cognitivista } & Ausubel & $\begin{array}{l}\text { Conhecimento prévio (ou conteúdo prévio ou conceito prévio), } \\
\text { subsunçor, estrutura cognitiva (ou estrutura hierárquica de } \\
\text { conceitos), aprendizagem significativa, assimilação, diferenciação } \\
\text { progressiva, reconciliação integrativa, organizadores prévios, } \\
\text { material potencialmente significativo. }\end{array}$ \\
\hline & Bruner & $\begin{array}{l}\text { Aprendizagem por descoberta (ou exploração dirigida de } \\
\text { alternativas), currículo em espiral, representação (ativa, icônica, } \\
\text { simbólica). }\end{array}$ \\
\hline & Piaget & $\begin{array}{l}\text { Esquemas, adaptação, assimilação, acomodação, organização, } \\
\text { equilibração, equilibração majorante, períodos (ou estágios) de } \\
\text { desenvolvimento. }\end{array}$ \\
\hline & Vergnaud & $\begin{array}{l}\text { Conceito, campos conceituais, situação (ou tarefa), invariantes } \\
\text { operatórios (teoremas em ação e/ou conceitos em ação), } \\
\text { esquemas. }\end{array}$ \\
\hline & Vygotsky & $\begin{array}{l}\text { Processos mentais superiores (processos internos, pensamento, } \\
\text { linguagem, comportamento voluntário), cultura, interação social, } \\
\text { mediação, zona de desenvolvimento proximal (ZDP), signos } \\
\text { (indicadores, icônicos e simbólicos). }\end{array}$ \\
\hline \multirow[t]{2}{*}{ Humanista } & Freire & $\begin{array}{l}\text { Dialogicidade (educação ou pedagogia dialógica, dialética entre o } \\
\text { ensinar e o aprender: educador e educando aprendem e ensinam } \\
\text { mutuamente), problematização (ou prática problematizadora), } \\
\text { libertação (ou educação como prática da liberdade, educação } \\
\text { emancipadora), educação bancária, criticidade, autonomia. }\end{array}$ \\
\hline & Novak & $\begin{array}{l}\text { Aprendizagem significativa, evento educativo (pensamentos, } \\
\text { sentimentos, ação), significados, mapeamento conceitual, } \\
\text { engrandecimento humano, elementos fundamentais: aprendiz, } \\
\text { professor, conhecimento, contexto, avaliação. }\end{array}$ \\
\hline
\end{tabular}

Fonte: Elaborado pelos autores com base nas obras de Lefrançois (2016) e Moreira (2011)

Cabe esclarecer que foi optado por não adicionar ao quadro 2 conceitos relacionados a Watson, Pavlov, Guthrie e Skinner, tendo em vista que esses teóricos apenas foram citados no trabalho de Lehmann (2010) como representantes do behaviorismo.

Como parâmetro para fins de comparação e classificação, utilizou-se a quantidade de descritores apresentadas na tabela 3, relacionadas a cada um dos teóricos de aprendizagem citados nos estudos.

Tabela 3. Frequência dos descritores (conceitos) para fins de classificação nas categorias

\begin{tabular}{clcccc} 
Filosofia & Teórico & $\begin{array}{c}\mathbf{N}^{\mathbf{0}} \text { de } \\
\text { descritores }\end{array}$ & $\begin{array}{c}\text { Não } \\
\text { embasado }\end{array}$ & $\begin{array}{c}\text { Parcialmente } \\
\text { embasado }\end{array}$ & $\begin{array}{c}\text { Fortemente } \\
\text { embasado }\end{array}$ \\
\cline { 2 - 5 } Behaviorismo & Thorndike & 8 & $0-2$ & $3-5$ & $6-8$ \\
& Ausubel & 9 & $0-2$ & $3-5$ & $6-9$ \\
Cognitivismo & Bruner & 3 & 0 & $1-2$ & 3 \\
& Piaget & 8 & $0-2$ & $3-5$ & $6-8$ \\
& Vergnaud & 5 & $0-1$ & $2-3$ & $4-5$ \\
& Vygotsky & 6 & $0-2$ & $3-4$ & $5-6$ \\
\multirow{2}{*}{ Humanismo } & Freire & 6 & $0-2$ & $3-4$ & $5-6$ \\
& Novak & 6 & $0-2$ & $3-4$ & $5-6$
\end{tabular}

Fonte: Os autores (2018) 
Ressalta-se que foi realizada uma análise de como a utilização dos descritores se deu em cada trabalho, com vistas a validar a classificação proposta. A síntese desta análise segue apresentada na sequência deste estudo, separadas segundo a abordagem teórica identificada.

\section{QUANTO AOS TRABALHOS MENCIONANDO TEÓRICOS BEHAVIORISTAS}

Foi identificado que apenas dois trabalhos (Lehmann, 2010; Pereira Filho, Kaiber e Lélis, 2012) citam teóricos behavioristas em seus escopos.

O primeiro deles é o de Lehmann (2010) que menciona Watson, Pavlov, Guthrie, Skinner e Thorndike como representantes da linha de pensamento behaviorista, porém, sem fazer distinção entre os pressupostos defendidos por um ou outro teórico. A autora descreve, em linhas gerais, que o behaviorismo se ampara na filosofia empirista e se baseia em condições externas e no comportamento dos sujeitos. Também traça considerações de como é uma escola fundamentada no behaviorismo e de como é o ensino de matemática nesta perspectiva.

Por outro lado, o trabalho de Pereira Filho e seus colaboradores (2012) tem como base um estudo de Cury (2007) para afirmar que Thorndike foi um dos grandes precursores na análise de erros, ao apresentar a "lei do exercício", cuja premissa é que o uso fortalece e o desuso enfraquece as "conexões mentais".

Cabe esclarecer que os trabalhos supracitados também mencionam teóricos do cognitivismo, cuja síntese será apresentada posteriormente. Contudo, apenas considerando os teóricos behavioristas, seria possível inferir que ambos trabalhos não se encontram embasados, uma vez que o de Lehmann (2010) não aborda nenhum conceito específico dos teóricos listados, e o de Pereira Filho, Kaiber e Lélis (2012) menciona de forma superficial apenas dois descritores de Thorndike: a "lei do exercício" e as "conexões mentais".

\section{QUANTO AOS TRABALHOS MENCIONANDO TEÓRICOS COGNITIVISTAS}

Neste quesito, constatou-se que vinte trabalhos estão relacionados aos teóricos cognitivistas. Os descritores mencionados em cada um desses trabalhos seguem apresentados por meio do quadro 3 .

Quadro 3. Descritores associados as TA cognitivistas

\begin{tabular}{|c|c|c|}
\hline Autoria & $\begin{array}{l}\text { Teórico(s) } \\
\text { citado(s) }\end{array}$ & $\begin{array}{c}\text { Conceitos principais relacionados as } \\
\text { TA citadas }\end{array}$ \\
\hline \multirow[t]{2}{*}{ Lehmann (2010) } & Piaget & $\begin{array}{l}\text { Estágios de desenvolvimento cognitivo, } \\
\text { assimilação, acomodação, organização. }\end{array}$ \\
\hline & Vygotsky & Interação social, cultura, ZDP. \\
\hline Kessler, Paula e Lemos (2011) & Vygotsky & $\begin{array}{l}\text { Mediação, pensamento, ZDP e processos } \\
\text { internos. }\end{array}$ \\
\hline Tofoli et al. (2011) & Vygotsky & Signo. \\
\hline \multirow[t]{3}{*}{ Kessler et al. (2011 } & Piaget & Nenhum dos conceitos é mencionado. \\
\hline & Vergnaud & Nenhum dos conceitos é mencionado. \\
\hline & Vygotsky & Interação, mediação, processos internos, ZDP. \\
\hline Almeida et al. (2011) & Piaget & $\begin{array}{l}\text { Equilibração, esquema, assimilação, } \\
\text { acomodação, estágios de desenvolvimento, } \\
\text { organização. }\end{array}$ \\
\hline Araújo et al. (2011) & Piaget & Nenhum dos conceitos é mencionado. \\
\hline \multirow[t]{3}{*}{ Kessler (2012) } & Piaget & Adaptação e equilibração. \\
\hline & Vergnaud & $\begin{array}{l}\text { Esquema, situação, tarefa, conceitos, conceito } \\
\text { em ação, teorema em ação, invariantes } \\
\text { operatórios. }\end{array}$ \\
\hline & Vygotsky & $\begin{array}{l}\text { Interação social, processos internos, linguagem, } \\
\text { mediação, ZDP. }\end{array}$ \\
\hline
\end{tabular}

11 


\begin{tabular}{|c|c|c|}
\hline \multirow[t]{3}{*}{ Braz, Mello e Silva (2012) } & Ausubel & Aprendizagem significativa. \\
\hline & Piaget & Nenhum dos conceitos é mencionado. \\
\hline & Vygotsky & Nenhum dos conceitos é mencionado. \\
\hline Teixeira e Pereira (2012) & Ausubel & $\begin{array}{l}\text { Conhecimento } \\
\text { significativa. }\end{array}$ prévio, $\quad$ aprendizagem \\
\hline $\begin{array}{l}\text { Pereira Filho, Kaiber e Lélis } \\
\text { (2012) }\end{array}$ & Piaget & Nenhum dos conceitos é mencionado. \\
\hline Sousa, Queiroz e Dantas (2013) & Piaget & $\begin{array}{l}\text { Equilibração, adaptação, assimilação, } \\
\text { acomodação, estágios do desenvolvimento, } \\
\text { organização, esquemas. }\end{array}$ \\
\hline Kessler (2013) & Vygotsky & Interação, ZDP, processos internos. \\
\hline \multirow{2}{*}{ Macambira e Atayde (2014) } & Piaget & Nenhum dos conceitos é mencionado. \\
\hline & Vygotsky & Nenhum dos conceitos é mencionado. \\
\hline Eberhardt e Parmegiani (2014) & Vygotsky & Interação social e mediação. \\
\hline Gerab e Trentin (2015) & Ausubel & Aprendizagem significativa. \\
\hline Müller e Zabala (2016) & Ausubel & $\begin{array}{l}\text { Subsunçor, assimilação, } \\
\text { significativa, } \\
\text { organizadores prévios, material potencialmente } \\
\text { significativo. }\end{array}$ \\
\hline \multirow[t]{2}{*}{ Mendonça et al. (2017) } & Ausubel & Aprendizagem significativa, conceitos prévios. \\
\hline & Vygotsky & Mediação, interação. \\
\hline Moriel Junior e Alencar (2017) & Vygotsky & ZDP, interação social. \\
\hline Pereira e Pasco (2017) & Vygotsky & Nenhum dos conceitos é mencionado. \\
\hline Palheta et al. (2017) & Bruner & $\begin{array}{l}\text { Aprendizagem por descoberta e currículo em } \\
\text { espiral. }\end{array}$ \\
\hline
\end{tabular}

Fonte: Autoria própria (2018), compilado a partir de informações dos trabalhos

Os dados do quadro 3 permitem afirmar que, segundo os critérios estabelecidos nesta investigação, quatro trabalhos (Araújo et al., 2011; Pereira Filho, Kaiber e Lélis, 2012; Macambira e Atayde, 2014; Pereira e Pasco, 2017) não estão embasados nas TA, visto que não mencionam nenhum dos conceitos elencados no quadro 2.

Os trabalhos de Araújo et al. (2011) e Pereira Filho, Kaiber e Lélis (2012) referem-se a Piaget em citações curtas, de forma breve, ligando este teórico ao construtivismo. O primeiro parafraseia Piaget, afirmando que o aprendizado também ocorre por meio da ativação de órgãos sensoriais partindo de estímulos externos (e não apenas pela percepção). Assim, o aprendizado implicaria em uma ação cognitiva do sujeito, na qual o conhecimento é construído (ARAÚJO et al., 2011). Já o trabalho de Pereira Filho, Kaiber e Lélis (2012) afirma que Piaget, por meio do construtivismo, exerceu muita influência no Brasil e isso possibilitou que muitos pesquisadores desenvolvessem estudos voltados à análise de erros.

A investigação de Macambira e Atayde (2014) faz alusão a Piaget e Vygotsky, entretanto, a referida pesquisa é decorrente da análise de um trabalho (levantado pelas autoras na revisão bibliográfica) que tinha esses autores como referência para a elaboração de estratégias pedagógicas.

Ao analisar os dados obtidos por meio de questionários aplicados a professores e alunos universitários, visando identificar critérios que levam alunos a terem um bom desempenho em Cálculo, o trabalho de Pereira e Pasco (2017) menciona o conceito "desenvolvimento real" como "[...] capacidade de aquisição de conhecimentos sem intermediários" (p. 6). Apesar de ser um conceito vygotskyano, que se encontra intimamente relacionado ao conceito de zona de desenvolvimento proximal (ZDP), "desenvolvimento real" foi considerado como um conceito secundário.

Além desses, outros três trabalhos (Tofoli et al., 2011; Braz, Mello e Silva, 2012; Gerab e Trentin, 2015) também seguem classificados como não embasados nas TA, haja vista a menção de apenas um dos conceitos relacionados no quadro 2.

Amparados em Vygotsky, o trabalho de Tofoli e seus colaboradores (2011) reforça a importância da formação de conceitos para que o aluno avance no processo de aprendizagem. No 
entanto, apenas o conceito de "signo" é citado como um meio pelo qual os sujeitos conduzem as operações mentais, controlam seu curso e canalizam em direção à solução dos problemas a serem enfrentados (VYGOTSKY, 1993 apud TOFOLI et al., 2011).

O trabalho de Braz, Mello e Silva (2012) menciona a importância de o professor ter um bom relacionamento com os alunos e de construir estratégias para a promoção da aprendizagem significativa (AS). Todavia, em nenhum momento é relatado ou aprofundado no artigo o que seria AS, assim como os conceitos principais associados a essa teoria. As autoras também parafraseiam Vygostsky (reforçando a importância de entender o aspecto emocional para compreender o aspecto cognitivo) e Piaget (afirmando que a aprendizagem ocorre na relação entre o que a pessoa sabe e o que o meio físico e social oferece), porém nenhum dos descritores associados aos dois teóricos é mencionado.

O trabalho de Gerab e Trentin (2015), cuja ênfase está na construção de mapas conceituais, menciona outros estudos que estão fundamentados na teoria da aprendizagem significativa (AS) de Ausubel, mas em nenhum momento tal conceito é definido pelos autores, assim como os demais pressupostos da AS.

Por fim, três trabalhos, citando dois descritores cada (Teixeira e Pereira, 2012; Eberhardt e Parmegiani, 2014; Moriel Junior e Alencar, 2017), também são qualificados como não embasados nas TA. O trabalho de Teixeira e Pereira (2012) traz conceitos fundamentais da teoria de Ausubel, como "conhecimento prévio" e "aprendizagem significativa", entretanto, não há um aprofundamento ou esclarecimentos acerca deles. Além disso, as autoras não citam em nenhum momento a obra de Moreira e Masini ${ }^{4}$ (1982) - única obra presente nas referências bibliográficas associada à AS - no trabalho.

Em sua investigação, Eberhardt e Parmegiani (2014) analisam a importância da articulação entre disciplinas de Cálculo e Física na formação dos engenheiros. Os autores argumentam sobre a importância da experimentação e defendem que vinculados a ela deve estar "[...] um referencial teórico que contempla o papel da interação social e dá importância à mediação simbólica" (EBERHARDT; PARMEGIANI, 2014, p. 3, grifos nossos). No entanto, da mesma forma que o estudo mencionado no parágrafo anterior, não há, ao longo do trabalho, maiores explanações acerca dos descritores vygotskyanos destacados ("interação social" e "mediação").

A pesquisa de Moriel Junior e Alencar (2017) apresenta a análise completa do MTSK (Mathematics Teacher's Specialized Knowledge), um modelo teórico que caracteriza o conhecimento profissional específico e especializado que um professor necessita para ensinar matemática, a partir de um artigo selecionado do mapeamento que realizaram. Segundo a análise dos autores, o texto em questão apresentava uma estratégia de ensino que incorporava conceitos da Teoria da Atividade, de Vygotsky, como ferramenta metodológica para aplicação de conceitos matemáticos do Cálculo. Dentre os conceitos utilizados estava o de "zona de desenvolvimento proximal" (ZDP), considerando que a atividade humana e os artefatos que servem para mediá-la com o mundo objetivo surgem através da "interação social". A exploração dos descritores destacados se limita a uma única frase e, consequentemente, não avança ao longo da pesquisa, da mesma forma como relatado nos trabalhos anteriores.

Em sua investigação, Mendonça et al. (2017) mencionam conceitos das teorias de Ausubel e Vygotsky. Em relação à primeira, inicialmente pontuam que o conceito de "aprendizagem significativa" surge como solução para a apatia, medo e insegurança do aluno diante do conteúdo apresentado. Em seguida, defendem a contextualização de "conceitos prévios" dos alunos com elementos do cotidiano a fim de estabelecer conexões e fortalecer o conteúdo trabalhado em sala. Quanto aos descritores associados à teoria de Vygotsky, os autores falam que a "mediação" da aprendizagem é um desafio para professores do século XXI e a definem como "[...] uma forma especializada de interação entre um sujeito que aprende e outro que ensina, assim favorecendo o processo de aprendizagem dos alunos" (MEIER, 2004 apud MENDONÇA et al., 2017, p. 2, grifo nosso).

Ainda considerando os trabalhos com enfoque cognitivista, cinco deles (Lehmann, 2010; Kessler, Paula e Lemos, 2011; Kessler et al., 2011; Kessler, 2013; Palheta et al., 2017) foram classificados como "parcialmente embasados".

O trabalho de Lehmann (2010) destaca as teorias da Epistemologia Genética (Piaget) e SócioHistórica (Vygotsky), sendo que descritores importantes de ambas teorias são abordados, conforme 
observa-se no quadro 3. Além disso, ao longo do trabalho a autora busca relacioná-los com o ensino de Matemática. Por fim, a pesquisadora apresenta uma síntese de alguns trabalhos realizados por diversas instituições com foco na disciplina de Cálculo I, mas não articula as TA (tratadas no referencial teórico) com eles.

O trabalho de Kessler, Paula e Lemos (2011) transita pelos conceitos vygotskyanos de mediação, pensamento, ZDP e processos internos. Inicialmente, defendem que parte do sucesso no processo de aprendizagem depende da qualidade da "mediação" (conceito que fora definido de forma genérica com base numa referência secundária de Vygotsky) pedagógica. Os autores também parafraseiam Vygotsky para tratar dos descritores supramencionados. Nesse sentido, afirmam que cognição e afeto precisam ser compreendidos de forma integrada no processo de ensino e aprendizagem, na medida em que para compreender o "pensamento" de forma completa é preciso compreender a base afetiva. Por fim, definem o que é ZDP e reforçam a importância da interferência de colegas, uma vez que esta interferência desperta vários "processos internos".

Analogamente, o trabalho de Kessler et al. (2011) também é considerado parcialmente embasado, tendo em vista que as autoras fazem menção a três teóricos - Piaget, Vergnaud e Vygotsky mas apenas descritores vygotskianos são citados. Reportando-se a Piaget, elas defendem que "[...] é na interação do sujeito com o objeto que determinadas estruturas cognitivas são construídas e reconstruídas" (KESSLER et al., 2011, p. 3). Em relação a Vergnaud, há citações diretas deste autor justificando a importância da linguagem no processo de aprendizagem.

Quanto aos pressupostos vygotskyanos, as autoras alegam que o trabalho se sustenta na abordagem sociointeracionista, "[...] que concebe a aprendizagem como um fenômeno que se realiza na interação como o outro" (KESSLER et al., 2011 p. 2, grifo nosso). Elas definem "mediação" por meio de uma citação de Oliveira ${ }^{5}$ (1997), cujo estudo ampara-se na teoria de Vygotsky. Além disso, parafraseiam Vygotsky pontuando que "[...] a aprendizagem desencadeia vários processos internos de desenvolvimento mental, que tomam corpo somente quando o sujeito interage com objetos e sujeitos em cooperação. Uma vez internalizados, esses processos tornam-se parte das aquisições do desenvolvimento" (KESSLER et al., 2011 p. 3, grifo nosso). Por fim, fazem uma citação direta de Vygotsky para definir a ZDP.

Novamente, preconizando se sustentar na abordagem sociointeracionista, "[...] que concebe a aprendizagem como um fenômeno que se realiza na interação com o outro" (KESSLER, 2013, p. 3, grifo nosso), o trabalho de Kessler (2013) alega também que

[...] as alterações no desempenho do aluno oportunizadas pela interferência de alguém são fundamentais na teoria de Vygotsky e podem ser explicadas por meio do conceito zona de desenvolvimento proximal (ZDP), compreendida como a distância entre o nível de desenvolvimento real, que se costuma determinar através da solução independente e o nível de desenvolvimento potencial, determinado através da solução de problemas sob a orientação de alguém ou em colaboração com colegas mais capazes” (KESSLER, 2013, p. 3, grifo nosso).

A autora parafraseia Vygotsky afirmando que as interferências de colegas despertam vários "processos internos", logo, é um momento importante para o desenvolvimento do aluno.

A investigação de Palheta e seus colaboradores (2017) ampara-se na teoria de Jerome Bruner, cuja premissa básica é que o processo de aprendizagem é realizado por meio da descoberta e da investigação de possibilidades. Os autores esclarecem que "[...] o método da descoberta consiste de conteúdos de ensino percebido pelo aprendiz em termos de problemas, relações e lacunas que ele deve preencher, a fim de que a aprendizagem seja significante e relevante" (PALHETA et al., 2017, p. 3). Para tanto, o ambiente para a "aprendizagem por descoberta" deve proporcionar alternativas, resultando no aparecimento de relações e similaridades. Além disso, os autores sugerem que o mesmo assunto seja trabalhado com distintas abordagens, formas de representação e níveis de dificuldade diferentes, isto é, que seja implementado o que Bruner denominou de "currículo em espiral".

Finalmente, para compor a última categoria, dos trabalhos com abordagem cognitivista considerados "fortemente embasados", tem-se quatro pesquisas (Almeida et al., 2011; Kessler, 2012; Sousa, Queiroz e Dantas, 2013; Müller e Zabala, 2016).

A partir da leitura do trabalho de Almeida et al. (2011), verifica-se que as autoras transitaram por seis descritores extremamente relevantes na teoria piagetiana. Um dos objetivos da investigação em 
questão era analisar, segundo a perspectiva de Piaget, os aspectos psicológicos do processo de aprendizagem de estudantes aprovados nos cursos de engenharia. Para tanto, aplicaram provas piagetianas de flutuação e do pêndulo, a fim de verificar se os estudantes possuíam o estágio operatório formal consolidado.

Nesse sentido, inicialmente, as autoras abordam aspectos mais amplos da teoria de Piaget mencionando que, segundo esse teórico, a aquisição de conhecimento se deve ao desenvolvimento cognitivo ("equilibração progressiva"), à linguagem, à internalização de "esquemas", à "assimilação e acomodação" e à interação social. Ou seja, a estrutura cognitiva é desenvolvida no decorrer da vida, quando cada "estágio de desenvolvimento" é caracterizado pelo aparecimento de estruturas originais (ALMEIDA et al., 2011).

Almeida et. al (2011) ainda argumentam que a "equilibração" é progressiva e é fruto da passagem de um estado menor de equilíbrio para um de maior equilíbrio. Também sugerem que a internalização de esquemas possibilita que o sujeito organize e acomode o conhecimento e, ao acomodálo, associe o mesmo a um esquema já existente ou a um novo esquema que será criado. Ao apresentar os resultados, as autoras traçam um panorama geral sobre os períodos de desenvolvimento propostos por Piaget, citando as principais características de cada fase. Por fim, com base nos resultados das provas aplicadas, concluem que os estudantes possuem as habilidades necessárias para o aprendizado de disciplinas matemáticas, como Cálculo.

A investigação de Kessler (2012) relata uma ação didática - desenvolvida por meio de uma comunidade de apoio virtual no ambiente Moodle - que almejava a melhoria da aprendizagem da disciplina Cálculo, ofertada na modalidade presencial. Apesar de serem mencionados três teóricos (Piaget, Vergnaud e Vygotsky), a autora deixa claro no resumo que o quadro teórico é centrado em Lev Vygotsky e Gerard Vergnaud.

Kessler (2012) explora de forma satisfatória a teoria dos campos conceituais de Vergnaud. Inicialmente, por meio de uma citação desse teórico, reforça os aspectos importantes a respeito da linguagem (bem como sua função) e do papel docente no sentido de oportunizar aos estudantes momentos para que explicitem suas concepções sobre as ações desenvolvidas em aula. Ao tratar do processo de aquisição de conceitos, a autora destaca a necessidade de que os "esquemas", definidos como a "[...] totalidade dinâmica organizadora da ação do sujeito para uma classe de situações especificada [...]" (VERGNAUD, 1996, p. 162 apud KESSLER, 2012, p. 7, grifo nosso), evocados pelos alunos em suas condutas sejam considerados. Dessa forma, o desenvolvimento cognitivo estaria relacionado ao desenvolvimento de um extenso repertório de esquemas.

Outrossim, Kessler (2012) define os termos "conceito em ação" e "teorema em ação" e afirma que eles estão contidos nos esquemas, podendo ser nomeados de forma mais abrangente como "invariantes operatórios", isto é, "[...] conhecimentos explicitados pelos estudantes e utilizados em suas ações diante de uma situação"(KESSLER, 2012, p. 8, grifo nosso). Além disso, a autora explora esses conceitos na prática, exemplificando-os a partir da produção dos alunos no ambiente virtual.

Ademais, pelo fato de sua investigação estar sustentada na abordagem sociointeracionista e de Vergnaud ter incorporado em sua teoria ideias vygotskyanas, Kessler (2012) cita descritores importantes associados a Vygotsky, a saber: interação social, linguagem, simbolização, processos internos, mediação, ZDP. Alguns desses destes conceitos são definidos no corpo do trabalho. Cabe mencionar ainda que os descritores "adaptação" e "equilibração" são mencionados como conceitos de Piaget que foram incorporados por Vergnaud em sua teoria.

Por sua vez, Sousa, Queiroz e Dantas (2013) exploram com riqueza de detalhes a teoria de Piaget, relacionando-a com o ensino. Os autores fazem um apanhado histórico sobre Piaget, destacando os maiores interesses deste teórico em suas investigações, e transitam com propriedade entre os conceitos de: "equilibração", "adaptação", "assimilação", "acomodação", "abstração empírica" e "abstração reflexionante", "estágios do desenvolvimento" e "esquemas". Ademais, falam acerca do construtivismo dentro da Epistemologia Genética e do método clínico desenvolvido por Piaget. Por fim, os autores justificam e associam aspectos da teoria aos resultados obtidos nos experimentos. 
O trabalho de Müller e Zabala (2016) faz referência à aprendizagem significativa. "Subsunçores" são definidos como conceitos considerados pré-requisitos ao novo aprendizado os quais "[...] podem ser mais ou menos estáveis, mais ou menos diferenciados, mas no processo de assimilação de um novo conceito, eles se modificam adquirindo novos significados" (MÜLLER; ZABALA, 2016, p. 4, grifo nosso). A definição de "aprendizagem significativa" também é apresentada pelos autores por meio de uma citação indireta de Moreira $^{6}$ (2011): “[...] a aprendizagem significativa é dinâmica, pois a interação entre os conbecimentos prévios e novos, que a caracteriza, é não literal (ou seja, substantiva) e não arbitrária (isto é, feita com elementos pré-existentes)" (MOREIRA, 2011 apud MÜLLER; ZABALA, 2016, p. 4, grifo nosso).

Na mesma perspectiva, Müller e Zabala (2016) também relacionam a teoria da aprendizagem significativa com o ensino de Cálculo, mencionando a falta de subsunçores por parte dos alunos e sugerindo o uso de "organizadores prévios" como recursos propostos por Ausubel para resolver esse problema. Neste sentido, definem, classificam (expositivo e comparativo) e exemplificam os organizadores prévios. Por fim, os autores mencionam a construção de objetos de aprendizagem e a pesquisa por outros materiais para serem disponibilizados aos alunos de Cálculo, relatando terem tido cuidado para que estes fossem "potencialmente significativos".

\section{QUANTO AOS TRABALHOS MENCIONANDO TEÓRICOS HUMANISTAS}

Em relação aos quatro trabalhos com enfoque humanista, três deles mencionam Paulo Freire e um menciona Novak, conforme apresentado no quadro 4, que também relaciona os descritores citados nos respectivos estudos.

Quadro 4. Descritores associados as TA humanistas

\begin{tabular}{|l|c|l|}
\hline \multicolumn{1}{|c|}{ Autoria } & $\begin{array}{c}\text { Teórico(s) } \\
\text { citado(s) }\end{array}$ & \multicolumn{1}{|c|}{$\begin{array}{c}\text { Conceitos principais relacionados as } \\
\text { TA citadas }\end{array}$} \\
\hline Bueno e Silva (2017) & Freire & Nenhum dos conceitos é mencionado. \\
\hline Costa et al. (2017) & Freire & Pedagogia dialógica. \\
\hline Xavier e Xavier (2017) & Freire & Dialogicidade, autonomia, modelo bancário. \\
\hline Gerab e Trentin (2015) & Novak & Aprendizagem significativa, mapas conceituais. \\
\hline
\end{tabular}

Fonte: Autoria própria (2018), compilado a partir de informações dos trabalhos

Segundo os critérios estabelecidos nesta investigação, entende-se que o trabalho de Bueno e Silva (2017) não está embasado na teoria de Paulo Freire, visto que não foi identificado nenhum dos descritores especificados no quadro 2, relacionados a este teórico. As autoras citam Freire em duas passagens: uma para justificar a implementação de uma disciplina inicial e outra para justificar a adoção de cartilhas didáticas. Ambas estratégias tinham como objetivo auxiliar os ingressantes nas disciplinas iniciais, especialmente em Cálculo I e Física I.

A primeira citação trata da dialética da mobilização: ninguém motiva ninguém, ninguém se motiva sozinho, os sujeitos se motivam em comunhão, mediados pela realidade. (BUENO; SILVA, 2017). Assim, as autoras argumentam que reuniões com o grupo de professores foram fundamentais para a tomada de decisão sobre a reformulação da matriz do curso de Engenharia Civil, o que culminou com a criação da disciplina de Fundamentos de Matemática e Física.

Num segundo momento, as autoras mencionam que seguindo o pensamento de Freire de que ensinar é criar possibilidades para que o conhecimento seja produzido e construído, novas alternativas didáticas pedagógicas estão sendo pesquisadas e implementadas na instituição que se constitui locus da pesquisa das autoras. Uma dessas alternativas foi a adoção de cartilhas didáticas para trabalhar as disciplinas de Física.

O trabalho de Costa et al. (2017) se direciona no mesmo sentido do de Bueno e Silva (2017). Neste caso, os autores também relatam práticas implementadas em uma instituição, a partir da constituição de um projeto, visando melhorar o desempenho de alunos no início de seus percursos formativos. 
Sob esse viés, Costa et al. (2017) citam Freire ao relatarem um dos princípios metodológicos que subsidiaram o projeto, o protagonismo. Para os autores, esse princípio é representado pela afirmação de que "[...] não há docência sem discência, as duas se explicam e seus sujeitos, apesar das diferenças que os conotam, não se reduzem à condição de objeto, um do outro. Quem ensina aprende ao ensinar, e quem aprende ensina ao aprender" (FREIRE, 1996, p. 23 apud COSTA et al., 2017, p. 3). Subentende-se que o referido trecho reforça a dialética entre o ensinar e aprender: educador e educando aprendem e ensinam mutuamente. Portanto, refere-se ao descritor "dialogicidade", de Freire. Um indicativo que reforça essa suposição é encontrado na conclusão, quando os autores afirmam se orgulhar em promover o protagonismo estudantil e fundamentar-se numa "pedagogia dialógica". De todo modo, como apenas um descritor é mencionado no trabalho de Costa e seus colaboradores (2017), infere-se que ele não esteja embasado na teoria freiriana.

O trabalho de Gerab e Trentin (2015) também foi classificado como não embasado, visto que menciona em seu escopo apenas dois descritores associados a Novak, a saber "mapas conceituais" (MC) e "aprendizagem significativa". Os autores defendem, com base em alguns estudos, que os MC podem possibilitar a formação reflexiva e interpretativa do que é estudado em uma disciplina, além disso, definem o conceito de MC a partir de uma citação de Ausbel. Em relação ao descritor "aprendizagem significativa", eles relatam alguns estudos que demonstram a relação entre este conceito e o mapeamento conceitual. No entanto, em nenhum momento os autores se aprofundam ou definem a aprendizagem significativa.

O trabalho de Xavier e Xavier (2017) apresenta relatos acerca da aplicação do Laboratório de Cálculo nas aulas da disciplina de Cálculo Diferencial. Os autores amparam-se em Freire para defender que o conhecimento não deve ser pré-transmitido, mas construído de forma conjunta por professores e alunos. Essa construção deve aceitar o novo, rejeitar toda a forma de discriminação e valorizar a identidade de cada um. Assim, percebe-se que o discurso de Xavier e Xavier (2017) reforça a importância da "educação dialógica".

Os autores ainda mencionam que Paulo Freire defendia uma prática educativo-progressista em favor da "autonomia" dos estudantes, em contraposição ao "modelo bancário" de educação que valoriza demasiadamente a memorização de conteúdos descontextualizados das realidades discentes e sem espaço para a reflexão crítica (XAVIER; XAVIER, 2017). Por entender que eles transitaram por três descritores importantes da teoria freiriana, o trabalho de Xavier e Xavier (2017) foi considerado parcialmente embasado.

Em resumo, com base nos critérios estabelecidos nesta pesquisa, pode-se afirmar que a maioria dos trabalhos $(n=13)$ não se encontra embasado nas TA mencionadas nos estudos. Percebe-se ainda que $27 \%$ dos trabalhos está parcialmente embasada $(n=6)$ e apenas $17 \%$ encontra-se fortemente embasado $(\mathrm{n}=4)$. Um panorama final desta classificação segue apresentado por meio do quadro 5.

Quadro 5. Classificação final dos trabalhos quanto ao embasamento nas TA

\begin{tabular}{|c|l|c|}
\hline Classificação & \multicolumn{1}{|c|}{ Autoria dos trabalhos } & Total \\
\hline $\begin{array}{c}\text { Não } \\
\text { embasados }\end{array}$ & ARAÚJO et al., 2011; TOFOLI et al., 2011; PEREIRA FILHO; KAIBER; & 13 \\
& LÉLIS, 2012; BRAZ; MELLO; SILVA, 2012; TEIXEIRA; PEREIRA, 2012; & \\
& EBERHARDT; PARMEGIANI, 2014; MACAMBIRA; ATAYDE, 2014; & \\
& $\begin{array}{l}\text { GERAB; TRENTIN, 2015; BUENO; SILVA, 2017; COSTA et al., 2017; } \\
\text { MENDONÇA et al., 2017; MORIEL JUNIOR; ALENCAR, 2017; }\end{array}$ & \\
& PEREIRA; PASCO, 2017. & \\
\hline $\begin{array}{c}\text { Parcialmente } \\
\text { embasado }\end{array}$ & LEHMANN, 2010; KESSLER et al., 2011; KESSLER; PAULA; LEMOS, & 06 \\
\hline $\begin{array}{c}\text { Fortemente } \\
\text { embasado }\end{array}$ & ALMEIDA et al., 2011; KESSLER, 2012; SOUSA; QUEIROZ; DANTAS, & 04 \\
\hline
\end{tabular}

Fonte: Os autores (2018) 
Pode-se supor que um embasamento teórico mais consistente nos trabalhos do COBENGE não foi possível devido à limitação do número de páginas exigida para propostas submetidas ao evento, que geralmente é reduzido quando comparado ao número de páginas (ou caracteres) possíveis para a submissão em periódicos. Talvez isso seja um impedimento para uma explanação mais detalhada do referencial teórico em detrimento das outras seções ou outros aspectos do trabalho.

Por outro lado, uma análise acerca do embasamento teórico realizada nos trabalhos de Jesus (2014) e Oliveira, Araujo e Veit (2017), cuja fonte para coleta de dados foram periódicos com boa qualificação na área de Ensino, revela conclusões semelhantes às alcançadas nesta investigação.

Jesus (2014) amparou-se em artigos publicados em quatro periódicos: um deles com Qualis A1 e três com Qualis A2. Usando como descritores o nome dos teóricos da aprendizagem, a autora relata que a maioria dos trabalhos se concentram na faixa de 1 a 4 ocorrências (isto é, o teórico da aprendizagem foi citado de 1 a 4 vezes no trabalho). Dessa forma, conclui que os autores dos artigos enquadrados nesta categoria não utilizaram aqueles descritores como seus referenciais teóricos. A pesquisadora afirma ter verificado que as citações utilizadas se referiam aos descritores de forma genérica e superficial; na maioria das vezes ocorriam breves citações no corpo do trabalho, notas de rodapé ou apenas citações na lista de referências bibliográficas (em obras originais ou não) (JESUS, 2014).

O trabalho de Oliveira, Araujo e Veit (2017) coletou artigos de 22 periódicos nacionais e internacionais: oito deles com Qualis A1, seis com Qualis A2 e oito com Qualis B1. Os autores concluem que os artigos analisados não possuem, em geral, embasamento em teorias de aprendizagem (OLIVEIRA; ARAUJO; VEIT, 2017).

Ressalta-se que, como este mapeamento caracteriza-se como de uma pesquisa descritiva, não coube aprofundar a reflexão sobre cada uma das teorias de aprendizagem indicada nos estudos. Para um melhor entendimento, recomenda-se leituras mais acuradas e específicas relacionadas a cada uma das TA.

\section{CONSIDERAÇÕES FINAIS}

A realização deste mapeamento permitiu verificar que, no período 2010-2017, o número de trabalhos voltados a disciplina de Cálculo Diferencial e Integral I $(n=75)$ publicados no COBENGE é ínfimo quando comparado ao total de estudos publicados no evento ( $\mathrm{n}=3.870)$. Dos 75 trabalhos levantados, verificou-se que $69 \%(\mathrm{n}=52)$ não mencionavam nenhum dos teóricos da aprendizagem que são foco deste estudo.

Desta forma, os 23 trabalhos identificados, aliando o ensino de Cálculo I a alguma teoria de aprendizagem, revelam que a produção na área é bastante tímida tendo um pequeno pico de crescimento em 2017, ano em que 7 trabalhos nessa perspectiva foram produzidos.

A pesquisa em tela também evidenciou que as teorias cognitivistas de Vygotsky, Piaget e Ausubel foram, nesta ordem, as mais citadas. No entanto, vale pontuar que "[...] não existe uma teoria infalível, que possa dar conta de explicar a aprendizagem em sua totalidade." (JESUS, 2014, p. 44). Portanto, o levantamento das TA mais citadas não tem o intuito de classificar uma teoria como mais importante ou superior a outra em termos absolutos. Defende-se que os professores poderão se beneficiar das contribuições advindas de todas as teorias, sendo que a reflexão acerca do processo de aprendizagem já se caracteriza como algo positivo, como um passo inicial.

Além disso, com base nos critérios estabelecidos neste estudo, observou-se que a maioria dos autores não mencionava $(n=13)$ ou mencionava poucos $(n=6)$ descritores fundamentais das TA no corpo dos trabalhos. Por este motivo, 19 dos 23 estudos analisados foram classificados como não embasados ou parcialmente embasados. Ressalta-se que, mesmo analisando periódicos científicos de grande relevância e com Qualis elevado na área de ensino, Jesus (2014) e Oliveira, Araujo e Veit (2017) também concluíram que parte significativa dos artigos não estavam embasados nas TA.

Talvez estes sejam indicativos de que não é dada a devida importância aos estudos realizados no campo da psicologia, especialmente os que tratam dos processos de aprendizagem. Os resultados deste mapeamento sugerem que discussões sobre a diversidade das formas de aprender, que levem em conta as particularidades dos aprendizes, ainda estão ausentes no contexto da disciplina de Cálculo, no âmbito da Educação em Engenharia. 
Sob tal ótica, apesar deste levantamento ser parcial e provisório, acredita-se que ele sirva para trazer pistas de investigação sobre as formas de aprender, ensinar e pensar os conteúdos de Cálculo I. Além do mais, tem-se a concepção que estudos voltados à temática das TA articuladas ao ensino de Cálculo são necessários, haja vista que um professor sem uma sólida (ou qualquer!) orientação teórica, também é responsável por parte das críticas negativas que são feitas à educação constantemente.

Nesse sentido, partindo das premissas de que todas as ações do professor são coloridas pela teoria psicológica por ele adotada, um profissional da área da educação que não faz uso de um corpo teórico sistemático em suas decisões diárias está agindo cegamente (BIGGE, 1977), posto que as TA trazem à luz aspectos importantes do processo de aprendizagem. Consequentemente, quando tais aspectos são compreendidos, internalizados e postos em prática pelos docentes, podem trazer avanços significativos no desempenho dos estudantes e resultados mais efetivos em sala de aula.

Portanto, infere-se que, por meio do estudo e da compreensão das TA e de seu desenvolvimento histórico, os professores poderão entender e lidar melhor com as situações e os conflitos que surgem nas salas de aula. Inclusive, poderão desenvolver novas propostas de intervenção, as quais estejam mais adequadas às suas realidades, a fim de auxiliar os estudantes na aquisição de conhecimento.

Frente aos desafios impostos no ensino dessa disciplina de Cálculo, cujo histórico é acompanhado por índices alarmantes de reprovação, talvez seja o momento de buscar subsídios adicionais para a tomada de decisão junto ao campo da psicologia, considerando os avanços e descobertas dessa área, especialmente no âmbito do desenvolvimento cognitivo. Um esforço que exigirá dos professores mudanças profundas na concepção de aprendizagem.

\section{REFERÊNCIAS}

ALMEIDA, D. D.; ARAÚJO, P. R.; SOUSA, G. M. C; RIBEIRO, T. R. L.R.; BARROS, M. T. A.; SANTOS, E. F. N. Fatores psicológicos e aprovação nas disciplinas básicas das engenharias In: XXXIX CONGRESSO BRASILEIRO DE EDUCAÇÃO EM ENGENHARIA, 2011, Blumenau. Anais... Blumenau (SC): FURB, 2011.

ANTUNES, C. Introdução à educação. São Paulo: Paulus, 2014. (Coleção Introduções).

ARAÚJO, P. R.; ALMEIDA, D. D.; SOUSA, G. M. C.; RIBEIRO, T. R. L. T.; BARROS, M. T. A. Reprovação nas disciplinas básicas: uma reflexão dos aspectos pedagógicos, na perspectiva dos docentes $\mathrm{e}$ discentes aprovados. In: XXXIX CONGRESSO BRASILEIRO DE EDUCAÇÃO EM ENGENHARIA, 2011, Blumenau. Anais... Blumenau (SC): FURB, 2011.

BECKER, F. Aprendizagem - concepções contraditórias. Revista Eletrônica de Psicologia e Epistemologia Genética, vol. 1, n. 1, p. 53-73, 2008. Disponível em: http:// www2.marilia.unesp.br/revistas/index.php/scheme/article/view/552. Acesso em: 8 de jan. 2018.

BIGGE, M. L. Teorias da aprendizagem para professores. São Paulo: EPU, 1977.

BRAZ, G. F.; MELLO, D. F. J.; SILVA, M. T. A. Estratégias pedagógicas vivenciadas em cursos de engenharia para o ensino de Cálculo: uma contribuição para a melhoria das relações de ensino e aprendizagem. In: XL CONGRESSO BRASILEIRO DE EDUCAÇÃO EM ENGENHARIA, 2012, Belém. Anais... Belém (PA): UFPA, 2012.

BUENO, L. S.; SILVA, P. D. Processo de ensino e aprendizagem em engenharia: uma proposta para a estruturação do ensino de Física e Cálculo no curso de engenharia civil da UNIARP. In: XLV CONGRESSO BRASILEIRO DE EDUCAÇÃO EM ENGENHARIA, 2017, Joinville. Anais... Joinville (SC): UDESC, 2017. 
COSTA, A. L. M.; SILVA, F. R. S.; CAVALCANTI, L. S.; SOARES, S. M. L.; PEREIRA, M. P. A.; MOURA, M. I. M.; SANTANA, P. C. F.; BEZERRA, A. S. Práticas pedagógicas integradas para o efetivo desempenho acadêmico do estudante de engenharia da Poli/UPE. In: XLV CONGRESSO BRASILEIRO DE EDUCAÇÃO EM ENGENHARIA, 2017, Joinville. Anais... Joinville (SC): UDESC, 2017.

CURY, H. N. COBENGE e ensino de disciplinas matemáticas nas Engenharias: um retrospecto dos últimos dez anos. In: XXX CONGRESSO BRASILEIRO DE ENSINO DE ENGENHARIA, 2002, Piracicaba. Anais.... Piracicaba (SP): UNIMEP, 2002. CD-ROM.

EBERHARDT, D.; PARMEGIANI, R. A implementação de experimentos de Física para auxiliar na compreensão de noções básicas de Cálculo. In: XLII CONGRESSO BRASILEIRO DE EDUCAÇÃO EM ENGENHARIA, 2014, Juiz de Fora. Anais... Juiz de Fora (MG): UFJF, 2014.

FIORENTINI, D.; GRANDO, R. C.; MISKULIN, R. G. S.; CRECCI, V. M.; LIMA, R. C. R.; COSTA, M. C. O professor que ensina matemática como campo de estudo: concepção do projeto de pesquisa. In: FIORENTINI, D.; PASSOS, C. L. B.; LIMA, R. C. R., (orgs.) Mapeamento da pesquisa acadêmica brasileira sobre o professor que ensina matemática: período 2001-2012. São Paulo: FE/UNICAMP, 2016. cap. 1, p. 17- 41.

FONTANA, D. Psicologia para professores. 2 ed. São Paulo: Manole, 1991.

FREIRE, P. Pedagogia da Autonomia: saberes necessários à prática educativa. São Paulo: Paz e Terra, 1996.

GERAB, F.; TRENTIN, P. H. T. A construção de mapas conceituais: uma metodologia ativa de aprendizagem para o Cálculo Diferencial e Integral no curso de engenharia. In: XLIII CONGRESSO BRASILEIRO DE EDUCAÇÃO EM ENGENHARIA, 2015, São Bernardo do Campo. Anais... São Bernardo do Campo (SP): CUFSA/MAUÁ/FEI/UFABC/UMESP, 2015.

GIL, A. C. Como elaborar projetos de pesquisa. 5. ed. São Paulo: Atlas, 2016.

GOMES, E. Ensino e aprendizagem do Cálculo na engenharia: um mapeamento das publicações nos COBENGES. In: XVI ENCONTRO BRASILEIRO DE ESTUDANTES DE PÓS-GRADUAÇÃO EM EDUCAÇÃO MATEMÁTICA, 2012, Canoas. Anais... Canoas (RS): ULBRA, 2012.

GOMES, R. C; COSTA, R. H.; NEVES, A. A.; SCHIMIGUEL, J.; SILVEIRA, I. F.; AMARAL, L. H. Teorias de aprendizagem: pré-concepções de alunos da área de exatas do ensino superior privado da cidade de São Paulo. Ciência \& Educação, v. 16, n. 3, p. 695-708, 2010. Disponível em: http://dx.doi.org/10.1590/S1516-73132010000300013. Acesso em: 17 de jan. 2018.

JESUS, L. G. As teorias de aprendizagem em pesquisas da área de educação em ciências: uma análise cienciométrica em periódicos brasileiros. 2014. 185 f. Dissertação (Mestrado) - Universidade Estadual do Sudoeste da Bahia, Bahia, 2014. Disponível em: http://www2.uesb.br/ppg/ppgecfp/wpcontent/uploads/2017/03/lucinea-gomes-de-jesus.pdf. Acesso em: 06 de jan. 2018.

KESSLER, M. C. Comunidades virtuais: novas práticas na busca da melhoria da aprendizagem do Cálculo Diferencial. In: XL CONGRESSO BRASILEIRO DE EDUCAÇÃO EM ENGENHARIA, 2012, Belém. Anais... Belém (PA): UFPA, 2012. 
KESSLER, M. C. Em busca da diminuição dos índices de repetência no Cálculo Diferencial: a experiência da Unisinos. In: XLI CONGRESSO BRASILEIRO DE EDUCAÇÃO EM ENGENHARIA, 2013, Gramado. Anais... Gramado (RS): UFRGS, 2013.

KESSLER, M. C.; PAULA, C. G.; LEMOS, R. S. M. PROMA: em busca de respostas para as repetências sucessivas no Cálculo Diferencial. 2011. In: XXXIX CONGRESSO BRASILEIRO DE EDUCAÇÃO EM ENGENHARIA, 2011, Blumenau. Anais... Blumenau (SC): FURB, 2011.

KESSLER, M. C.; PY, M.; MANZINI, N. I. J.; LEMOS, R. S. M. Apoio virtual vídeo-interativo: uma possibilidade na melhoria da aprendizagem dos acadêmicos da Unisinos. In: XXXIX CONGRESSO BRASILEIRO DE EDUCAÇÃO EM ENGENHARIA, 2011, Blumenau. Anais... Blumenau (SC): FURB, 2011.

LA ROSA, J. Introdução. In: LA ROSA (org.). Psicologia e educação: o significado do aprender. Porto Alegre: EDIPUCRS, 2007. p. 15-22.

LEFRANÇOIS, G. R. Teorias de aprendizagem: o que o professor disse. São Paulo: Cengage Learning, 2016.

LEHMANN, M. S. O processo de ensino-aprendizagem de disciplinas de Cálculo em cursos de engenharia: análise das teorias e práticas pedagógicas. In: XXXVIII CONGRESSO BRASILEIRO DE EDUCAÇÃO EM ENGENHARIA, 2010, Fortaleza. Anais... Fortaleza (CE): 2010.

LODER, L. L. Epistemologia versus pedagogia: o locus do professor de engenharia. 2002. $229 \mathrm{f}$. Dissertação (Mestrado) - Universidade Federal do Rio Grande do Sul, Porto Alegre, 2002. Disponível em: http://www.lume.ufrgs.br/handle/10183/2983. Acesso em: 20 de dez. 2017.

MACAMBIRA, I. Q.; ATAYDE, L. S. Reprovação na disciplina de Cálculo nos cursos de Engenharia: análise de dados e métodos minimizadores. In: XLII CONGRESSO BRASILEIRO DE EDUCAÇÃO EM ENGENHARIA, 2014, Juiz de Fora. Anais... Juiz de Fora (MG): UFJF, 2014.

MENDONÇA, J. C. F.; BARBOSA, R. L.; LADEIRA, A. P.; XAVIER, P. O. C.; XAVIER, A. F. A.; REZENDE, L. B. O. Uma experiência inovadora em sala de aula: aprendizagem significativa nas aulas de Cálculo Diferencial. In: XLV CONGRESSO BRASILEIRO DE EDUCAÇÃO EM ENGENHARIA, 2017, Joinville. Anais... Joinville (SC): UDESC, 2017.

MIZUKAMI, M. G. N. Ensino: as abordagens do processo. São Paulo: EPU, 2011.

MOREIRA, M. A. Teorias de Aprendizagem. 2 ed. ampl. São Paulo: EPU, 2011.

MOREIRA, M. A. Aprendizagem significativa: a teoria e textos complementares. São Paulo: Ed. Livraria da Física, 2011.

MOREIRA, M. A.; MASINI, E. F. S. Aprendizagem significativa: a teoria de aprendizagem de David Ausubel. São Paulo: Moraes, 1982.

MORIEL JUNIOR, J. G.; ALENCAR, A. P. Conhecimentos especializados para ensinar Cálculo em engenharias: uma análise de artigos do COBENGE. In: XLV CONGRESSO BRASILEIRO DE EDUCAÇÃO EM ENGENHARIA, 2017, Joinville. Anais... Joinville (SC): UDESC, 2017. 
MÜLLER, T. J.; ZABALA, F. J. Avaliação de uma sequência didática para amenizar dificuldades em Cálculo. In: XLIV CONGRESSO BRASILEIRO DE EDUCAÇÃO EM ENGENHARIA, 2016, Natal. Anais... Natal (RN): UFRN, 2016.

NEHIRING, C. M.; PIVA, C.; KINALSKI, N. Uma análise das produções nos COBENGEs - debate na área de Matemática. In: XXXV CONGRESSO BRASILEIRO DE ENSINO DE ENGENHARIA, 2007, Curitiba. Anais... Curitiba (PR): UniceP, 2007. CD-ROM.

OLIVEIRA, M. K. Vygotsky: aprendizado e desenvolvimento - um processo sócio-histórico. São Paulo: Scipione, 1997.

OLIVEIRA NETTO, A. A. Metodologia da pesquisa científica: guia prático para a apresentação de trabalhos acadêmicos. 3. ed. rev. e atual. Florianópolis: Visual Books, 2008.

OLIVEIRA, V.; ARAUJO, I. S.; VEIT, E. A. Resolução de problemas abertos no ensino de física: uma revisão de literatura. Revista Brasileira de Ensino de Física, vol. 39, n. 3, p. 1-17, 2017. Disponível em: http://www.scielo.br/scielo.php?script=sci arttext\&pid=S1806$11172017000300502 \& \operatorname{lng}=p t \& t \operatorname{lng}=$ pt. Acesso em: 4 de fev. 2018.

PALHETA, F. L.; LISBOA, M. M.; OLIVEIRA, J. M. C.; RODRIGUES, A. G.; COSTA, J. B. C.; LOPES, A. M. S. Avaliação da aplicação de uma atividade de monitoria em uma disciplina de Cálculo. In: XLV CONGRESSO BRASILEIRO DE EDUCAÇÃO EM ENGENHARIA, 2017, Joinville. Anais... Joinville (SC): UDESC, 2017.

PEREIRA, V. F.; PASCO, M. T. Percepções de aluno e professor na abordagem de critérios de importância e desempenho no estudo da disciplina de Cálculo. In: XLV CONGRESSO BRASILEIRO DE EDUCAÇÃO EM ENGENHARIA, 2017, Joinville. Anais... Joinville (SC): UDESC, 2017.

PEREIRA FILHO, A. D.; KAIBER, C. T.; LÉLIS, F. R. C. Categorização e análise de erros Cálculo Diferencial e Integral. In: XL CONGRESSO BRASILEIRO DE EDUCAÇÃO EM ENGENHARIA, 2012, Belém. Anais... Belém (PA): UFPA, 2012.

SOUSA, G. M. C.; QUEIROZ, S. S.; DANTAS, D. S. C. Avaliação de desenvolvimento cognitivo de estudantes de engenharia numa perspectiva piagetiana. In: XLI CONGRESSO BRASILEIRO DE EDUCAÇÃO EM ENGENHARIA, 2013, Gramado. Anais... Gramado (RS): UFRGS, 2013.

TEIXEIRA, K. C. B.; PEREIRA, A. C. C. Os conhecimentos prévios de matemática trazidos pelos alunos ingressantes nos cursos de engenharia da UNIFOR: atual cenário. In: XL CONGRESSO BRASILEIRO DE EDUCAÇÃO EM ENGENHARIA, 2012, Belém. Anais... Belém (PA): UFPA, 2012.

TOFOLI, F. L.; OLÍVIA, F. A.; SILVA, V. A.; VALTER, J. S. Utilização de exemplos práticos no contexto da eletrônica de potência para o ensino de Cálculo Diferencial e Integral em cursos de graduação em Engenharia Elétrica. In: XXXIX CONGRESSO BRASILEIRO DE EDUCAÇÃO EM ENGENHARIA, 2011, Blumenau. Anais... Blumenau (SC): FURB, 2011.

TOZZI, M. J.; DUTRA, S. C. O congresso brasileiro de educação em engenharia - COBENGE. Revista de Ensino de Engenharia, vol. 32, n. 3, p. 25-36, 2013. Disponível em: http://107.161.183.146/ abengeorg/revista/index.php/abenge/article/view/234. Acesso em: $16 \mathrm{de}$ dez. 2017. 
TUNES, E.; TACCA, M. C. V. R.; MARTÍNEZ, A. M. Uma crítica às teorias clássicas da aprendizagem e à sua expressão no campo educativo. Linhas Críticas, v. 12, n. 22, p. 109-130, 2006. Disponível em: http://periodicos.unb.br/index.php/linhascriticas/article/view/1688. Acesso em: 8 de jan. 2018.

VYGOTSKY, L.S. Pensamento e Linguagem. São Paulo: Martins Fontes, 1989.

VYGOTSKY, L. S. A formação social da mente: o desenvolvimento dos processos psicológicos superiores. 6. ed. São Paulo: Martins Fontes, 1998.

XAVIER, A. F. A.; XAVIER, P. O. C. Laboratório de Cálculo: Gameficação das disciplinas de exatas. In: XLV CONGRESSO BRASILEIRO DE EDUCAÇÃO EM ENGENHARIA, 2017, Joinville. Anais... Joinville (SC): UDESC, 2017.

YIN, R. K. Pesquisa qualitativa do início ao fim. Porto Alegre: Penso, 2016.

\section{NOTAS}

${ }^{1}$ Neste estudo a Engenharia será considerada como campo; a Educação em Engenharia será tratada como uma área ou linha de pesquisa contida no campo da Engenharia.

${ }^{2}$ Os trabalhos em questão foram realizados por Cury (2002) e Nehring (2007). Ambos tinham como foco o ensino de Matemática nas engenharias, sendo que a coleta e análise de dados se deu a partir dos anais do COBENGE, nos períodos 1992-2001 e 2004-2006, respectivamente.

${ }^{3}$ Um dos trabalhos (Gerab e Trentin, 2015) referenciou a versão inglesa: The acquisition and retention of knowledge: a cognitive view, considerada equivalente a versão portuguesa.

${ }^{4}$ A obra em questão é: MOREIRA, M. A.; MASINI, E. F. S. Aprendizagem significativa: a teoria de aprendizagem de David Ausubel. São Paulo: Moraes, 1982.

${ }^{5}$ OLIVEIRA, M. K. Vygotsky: aprendizado e desenvolvimento - um processo sócio-histórico. São Paulo: Scipione, 1997.

${ }^{6}$ MOREIRA, M. A. Aprendizagem significativa: a teoria e textos complementares. São Paulo: Ed. Livraria da Física, 2011.

Submetido: $03 / 08 / 2018$

Aprovado: 05/10/2019

Contato:

Edinéia Zarpelon Universidade Tecnológica Federal do Paraná (UTFPR) Via do Conhecimento, $\mathrm{s} / \mathrm{n}-\mathrm{km} 01$ Pato Branco | Paraná (PR) | Brasil CEP 85503-390 